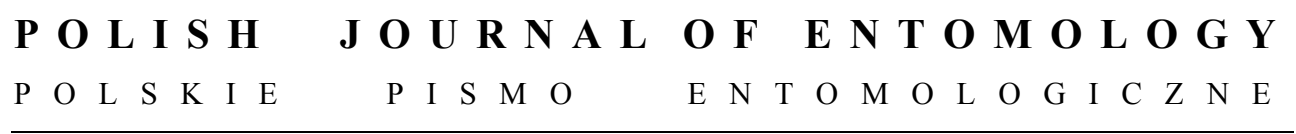

VOL. 82: 389-396

Gdynia

31 December 2013

DOI: $10.2478 /$ pjen-2013-0002

\title{
Two new species of the genus Suillia ROBINEAU-DESVOIDY, 1830 from southern Asia (Diptera: Heleomyzidae: Suilliinae)
}

\author{
ANDRZEJ J. WOŹNICA \\ Institute of Biology, Wrocław University of Environmental \\ \& Life Sciences, Kożuchowska 5b, 51-631 Wrocław, Poland, \\ e-mail: andrzej.woznica@up.wroc.pl
}

\begin{abstract}
Two new species, Suillia niesiolowskii from India and Suillia incognita from China are described and illustrated.
\end{abstract}

KEY WORDS: Diptera, Heleomyzidae, Suilliinae, Suillia, taxonomy, new species, Asia.

\section{INTRODUCTION}

Suillia RoBINEAU-DESVOIDY, 1830 is the genus with the greatest number of species within the family Heleomyzidae. Hitherto 129 have been described (WoŹNICA 2007), especially in the Palaearctic. Nevertheless, some mountain areas, especially in southern Asia, are very poorly known in this respect. The present paper describes two hitherto unknown species from this genus.

\section{Acknowledgments}

I would like to express my sincere thanks to $\mathrm{Mr} \mathrm{N}$. Wyatt and Mr David Notton (formerly BMNH) and to Dr Roy Andersson (LUZ) for providing the unidentified material for study and for making these specimens available for examination.

\section{MATERIAL AND METHODS}

Details of the male terminalia were observed in lateral position using a light microscope and computer techniques. Photographs were taken with a Canon G9 digital camera attached 
to a Zeiss Primo Star light microscope using computer graphic techniques (Photoshop and Corel Draw). The genitalia are preserved in glycerin vials. Bilaterally symmetrical structures are treated as singular in the descriptions. Holotype and paratype label data are quoted as they appear; a slash (/) indicates the end of a line of print, two slashes (//) signify data on a further label. The terminology of the external structures and male terminalia is after WoźNICA (2006). Abbreviations of measurements follow WoźNICA (2003).

\section{TAXONOMY}

\section{Suillia niesiolowskii sp. $\mathbf{n}$.}

(Figs 1-5)

\section{Diagnosis}

S. niesiolowskii is similar to S. mirabilis WoźNICA, 2004 described from the same locality (Kodaikanal, South India). The new species differs in having a thin dark brown stripe outside the dorsocentrals and 3 spherical seminal capsules. S. mirabilis is larger $(7.20-8.45 \mathrm{~mm})$, has a homogeneously orange-brownish mesonotum, dark brown lateral margins of all postabdominal segments, and 2 of 3 seminal capsules armed with distinct vermicular appendices (WoŹNICA 2004).

\section{Description}

Body length (without antennae) 4.1-4.3 mm.

Head. Eye big and slightly elliptical. Head ratio about 1.1. Flag-cheek ratio about 1.251.27. Cheek to eye ratio ca 0.2 . Orbital plate parallel to eye margin, anterior part of frons yellowish-orange, posterior part behind orbital bristle orange. Ocellar triangle between ocelli brownish. Hind part of head pale orange and shiny. Face slightly protuberant and with lower part orange-brownish. Gena yellowish-brown (wide brown area from the base of vibrissae to middle genal part) with one black vibrissa and a second additional bristle (ca $1 / 2$ of the upper one). Palpus yellowish at base, dark brown in the one-fourth apical part. Proboscis yellowish-orange. Supracervical setulae black.

Scape and pedicel orange. First flagellomere oval, orange-brownish. Arista long, plumose. Upper microtrichia distinctly longer than those from the lower row.

Thorax. Prosternum yellowish. Mesonotum and scutellum yellowish-orange and rather shiny, with dorsocentrals arising from thin pale yellow spots, An indistinct brownish stripe present between dorsocentrals and rising to scutellum (v-shaped and better visible here).

A pair of thin dark brown stripes present outside the dorsocentrals. Pleural parts and postscutellum basically yellowish-orange. Dorsal part yellowish-red with 5 pairs of dorsocentrals, not arising from dark spots. Pleura with distinct brownish stripe from lateral margin of postpronotum to base of wing. Anterior corner of anepisternum above coxa with 
small dark brown spotted area. Proepisternum with a few (less than 7) brown setulae. Anepisternum near the suture in the upper area setulose with less than 20 dark brown setulae. Katepisternum with 1 strong black bristle and some small hairs, with thin, dark brown mark in the lower corner. Anepimeron bare. Upper hind corner of meron and metapleuron covered by few pale brown setulae. Scutellum slightly pointed apically, with several (c. 11-15) black setulae laterally. Postscutellum bare.

Wings. Length ca $6.3 \mathrm{~mm}$, width $2.5 \mathrm{~mm}$. Black costal spines well developed, especially before costal break. Veins pale brown. Membrane regularly brown dusted Longitudinal veins and especially their apical area more brownish dusted. Cross-vein area dark brown. Medial vein ratio ca 1.656 in the holotype. Haltere pale orange, club setulose.

Legs. Ground colour yellowish orange. In male ventral parts of all femora with long yellow hairs. Mid femur with 4-5 black bristles anteriorly. Hind femur with 8-10 black subapical dorsolateral bristles arranged in two rows. All tibiae long haired ventrally, especially mid tibia. Tarsomeres 3-5 of all tarsi brownish.

Abdomen. Basic colour of segments orange, first five tergites in the $1 / 3$ hind part brownish-grey and with long black marginal bristles. Tergite VI larger than others and yellowish-orange. Three well sclerotized, brown and rounded seminal capsules present.

Male terminalia. Epandrium yellowish-brown, sparsely covered by short setulae, slightly longer than wide, with very long haired cerci. Gonostylus symmetrical (Figs 1a-b), L-shaped laterally, long haired dorsally, slightly arched outwardly with an inner appendix in the ventral hind part. Ventral part sparsely haired with some thorn-like setulae, especially in the apical part. Phallapodeme as in Fig. 2. Ejacapodeme spoon-like. Pregonite buttonlike and covered by several setulae, postgonite with distinctly longer setulae (Fig. 3) with two big setulae in the apical part. Basiphallus and distiphallus as for the genus (Fig. 4).

Female terminalia. Postabdomen short, segments short setulose only. Sternite VI and VII wider than long. Sternite VI rectangular, sternite VII trapezoidal and slightly longer than VI. Cerci ovoid, pale brown and separated, sparsely hairy. Three round glossy and well sclerotized brown seminal capsules (Fig. 5), with transparent twisted spermathecal ducts.

Type material

Holotype male: Kodaikanal 7000ft.; / S. India. 23-III-36 (below: B.M.- C.M. / Expedn to; / S. India. 1936). The holotype is deposited at the Natural History Museum, London.

Paratypes: 2 females: Kodaikanal 7000ft.; S. India. / 24-III-36 (below: B.M.- C.M. / Expedn to; / S. India. 1936). 1 female: Kodaikanal 7000ft.; S. India. / 23-III-36 (below: B.M.C.M. / Expedn to; / S. India. 1936). All type specimens with red framed label: Suillia / niesiolowskii / WoźNICA sp. nov.

In two females one wing destroyed. Genitalia of the holotype and one paratype female prepared and kept in glycerine microvial. 


\section{Etymology}

The species is named in honour of Professor Stefan Niesiołowski, in recognition of his important contributions to the study of Diptera in Poland.

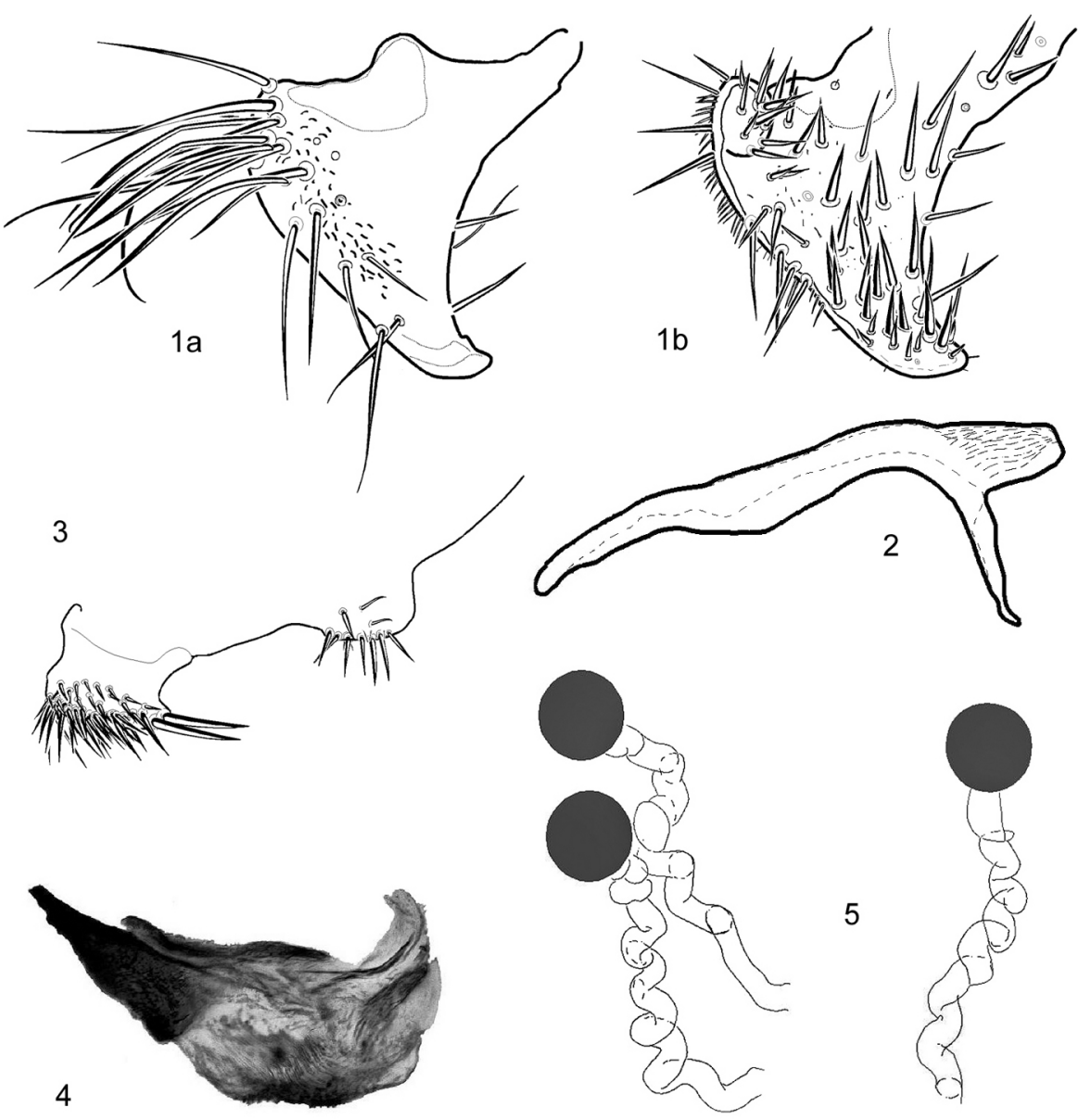

Figs 1-5. Suillia niesiolowskii: 1a - left gonostylus on outer surface, $1 \mathrm{~b}$ - right gonostylus on outer surface, 2 - phallapodeme, lateral view, 3 - gonite complex (postgonite and pregonite), lateral view, 4 - distiphallus complex, lateral view, 5 - seminal capsules, lateral view. 


\section{Suillia incognita sp. $\mathbf{n}$.}

(Figs 6-9)

\section{Diagnosis}

The new species is similar to $S$. gorodkovi OKADOME, 1968 known only from Honshu (Japan) (OKADOME 2001). Differs in having palpi brown apically, a thin brownish black stripe from the base of the postpronotum to the base of the wing and the abdomen totally brown. In $S$. gorodkovi the arista is practically bare, palpi are completely yellowish and abdomen blackish (OKADOME 1968).

\section{Description}

Body length (without antenna) ca $7.0 \mathrm{~mm}$.

Head. Eye round, cheek to eye ratio ca 0.3. Head ratio 1.2. Flag-cheek ratio 0.9. Middle part of face slightly protruberant. Anterior margin of the frontal plate covers the first antennal segments. One big vibrissa present. Area between eye corner and base of vibrissa dark brown spotted. Face brownish-yellow. Anterior part of orbital plate pale brown, posterior part darker in colour, ocellar triangle dusted greyish. One strong orbital bristle present. Supracervical setulae blackish. Genal setulae black and arranged in three irregular rows. Palpus thin, and yellowish except one-third brown apical part. Proboscis brown.

Scape and pedicel orange. First flagellomere elongated and pubescent, slightly narrowed to apex, externally orange-brownish, flag (first flagellomere) ratio less than 1.63. Arista brown and long pubescent.

Thorax. Prosternum yellowish, with 3 pairs of minute, thin brown and shiny golden hairs in the upper part. Mesonotum brownish and pale dusted greyish. Only notopleural area around anterior notopleural bristle haired. Postpronotum the same colour as mesonotal disc. Dorsocentral bristles (1+4 pairs) arising from minute irregular brown dots. Proepimeron, anepisternum, katepisternum brown and distinctly darker in colour than other pleural parts. One big katepisternal bristle present. Anepimeron paler in colour with 6-8 dark brown hairs in anterior corner, remaining part of pleurae bare. Scutellum totally orange-brown, with numerous (less than 15) setulae on disc covering area between scutellar bristles. Lower part of scutellum covered by relatively thin and long brownish setulae. Postscutellum brownish.

Legs. Basic colour of all legs yellowish-brown. All coxae paler. Fore femur dark brown and dusted grey anteriorly with 7 anterodorsal and 5 irregular posteroventral bristles apically. Fore femur with long and thin hairs in the lower part. Mid femur with some small black spine-like bristles grouped in two rows on posterior one-third apical ventral part. Mid femur with 3 bristles in anterior part and some hair-like bristles. Hind femur with 3 black long anterodorsal bristles. Mid and hind femora moderately haired. All tibiae yellowishbrown and short setulose only. Apical parts of all tibiae slightly darker (brown). Preapical bristles well developed. 


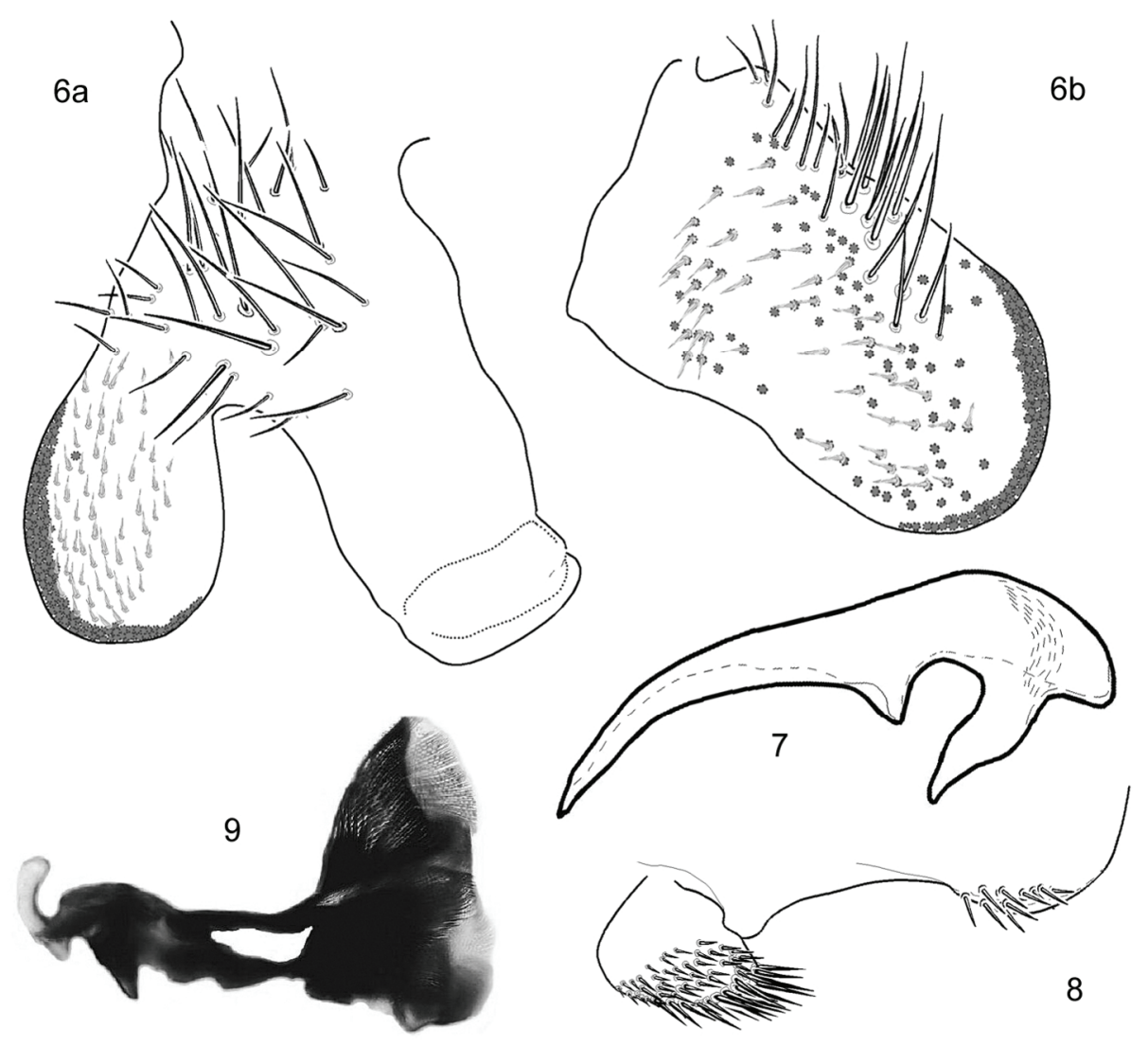

Figs 6-9. Suillia incognita: $6 \mathrm{a}$ - right gonostylus on outer surface, $6 \mathrm{~b}$ - left gonostylus on outer surface, 7 - phallapodeme, lateral view; 8 - gonite complex (postgonite and pregonite), lateral view, 9 - distiphallus complex, lateral view.

Tarsomeres 3-5 of fore leg and 4-5 of mid and hind tarsi dark brown. First tarsomere of fore and hind legs with shiny golden comb-like setulae. Tibia with comb of shiny gold teeth. Tarsomeres 2-4 of mid leg with black spine-like setulae laterally.

Wing. Membrane brown tinged. Veins brown. Costal spines black and short, but longer than width of costa. Both cross-veins distinctly brown and with dark brown surrounding areas. Vein cu (last longitudinal) totally brown. Medial vein ratio ca 1.275. Haltere paleorange with more brownish and minutely setulose knob. Wing length $6.5 \mathrm{~mm}$, width 2.7 $\mathrm{mm}$. Subcostal area dark brown, upper half of the first longitudinal area dusted dark brown with pale whitish triangular area apically. 
Abdomen. Segments brownish with dark brown margins. Epandrium brownish. Cerci small, elongate, long haired. Abdomen sparsely setulose. Marginal bristles black and relatively thick.

Male terminalia. Epandrium sparsely covered with short setulae, big and slightly higher than wide, with elongated and long haired cerci, yellowish-brown in colour. Gonostylus asymmetrical (Figs 6a-b). Right-hand gonostylus bilobed and sparsely covered with long setulae (Fig. 6a) on the outer surface. Inner part sparsely haired with some thorn-like setulae in the lower fore branch (Fig. 6b). Phallapodeme as in Fig. 7. Ejacapodeme medium sized and root-like. Pregonite semicircular and covered by a few setulae, postgonite setulose with some big setulae in the apical part (Fig. 8). Basiphallus and distiphallus complex in structure. Apical part of distiphallus flattened and shovel-like (Fig. 9).

\section{Type material}

Holotype, male: China Hunan / Tien-Chan Shan / \pm 1200m VII-VIII. 1938 / coll. G./ Österlin (LUZ) // Suillia $\widehat{~} /$ incognita / WoźNICA sp. nov.

In the holotype the left wing is destroyed in the $1 / 3$ apical part. Left first flagellomere missing. The abdomen was cut behind the first abdominal segment, prepared and stored in a glycerine microvial.

\section{Etymology}

The specific name incognita deriving from Latin refers to the discovery of hitherto unknown species.

\section{REFERENCES}

CZERNY L. 1924. Monographie der Helomyziden. Abhandlungen der zoologisch-botanischen Gesellschaft in Wien 15: 1-166.

CzERNY L. 1935. Ergänzungen zu meiner Monographie der Helomyziden, IX, Konowia 14: 271-287.

DeEming J.C. 1966. Diptera from Nepal (Heleomyzidae). Bulletin of the British Museum, Entomology 17: 435-438.

Gorodkov K.B. 1965. On the forest fauna of Helomyzid flies (Diptera) of Eastern Siberia and the Far East of the USSR. Entomologicheskoe Obozrenie 44: 927-933. [In Russian].

GoRodKov K.B. 1977. New species of the family Helomyzidae (Diptera) from the Asiatic Part of the USSR. Entomologicheskoe Obozrenie 56: 211-222. [In Russian].

GorodKov K.B. 1984. Family Heleomyzidae (Helomyzidae). [In:] Soós A., PAPP L. (eds). Catalogue of Palaearctic Diptera. Vol. 10, Budapest, pp.: 15-45.

Okadome T. 1985. Five new Suillia from Oriental Region (Diptera: Heleomyzidae). International Journal of Entomology 27: 217-223.

OKADOME T. 1991. Heleomyzid flies of Pakistan (Diptera). Japanese Journal of Entomology 59: 425-434.

OKAdome T. 2001. Two new and two newly-recorded species of the genus Suillia R.-D. from Japan (Diptera : Heleomyzidae), with a key to the Japanese species. Entomological Science 4: 185-190.

WoźNICA A. 2003. Two new synonyms of the Old World representatives of the genus Suillia Robineau-Desvoidy, 1830 (Diptera: Heleomyzidae: Suilliinae). Polskie Pismo Entomologiczne 72: 349-357. 
WoźNICA A. 2004. A new species of the genus Suillia RoBInEAU-Desvoldy, 1830 (Diptera: Heleomyzidae: Suilliinae) from India. Polskie Pismo Entomologiczne 73: 299-305.

WoźnicA A. 2006. Three new species of the genus Suillia RobinEAU-Desvoidy, 1830 from the Neotropical Region (Diptera: Heleomyzidae). Annales Zoologici 56: 657-665.

Woźnica A. 2007. Two new species of the genus Suillia Robineau-Desvoidy, 1830 from Oriental Region (Diptera: Heleomyzidae: Suilliinae). Polskie Pismo Entomologiczne 76: 303-311.

Received: 1 December 2013

Accepted: 6 December 2013 